\title{
TRANSFUSION TRANSMITTED HEPATITIS- A STUDY AMONG BLOOD DONORS
}

\author{
Lekshmi Leela Rajan', M. S. Suma², Harikumar $S^{3}$
}

${ }^{1}$ Associate Professor (CAP), Department of Transfusion Medicine and Immunohematology, Government Medical College, Kollam, Kerala, India.

${ }^{2}$ Additional Professor, Department of Transfusion Medicine and Immunohematology, Government Medical College, Kottayam, Kerala, India.

${ }^{3}$ District Programme Manager, National Health Mission, Kerala, India.

\section{BACKGROUND}

ABSTRACT

WHO has aimed the global elimination of Hepatitis B and Hepatitis C by 2030. Hepatitis B and hepatitis C are the major causes of acute and chronic liver diseases and they usually spread via infected body fluids. Prevalence study of these two infections in the community is very important to tackle the spread of the disease. Large scale population-based studies are lacking. Blood donors are routinely screened for these infections. Even though the actual prevalence in the community is much higher than in donor population, the prevalence study of viral hepatitis in donor population gives an idea about the magnitude of the illness in the community.

\section{MATERIALS AND METHODS}

The study is a descriptive study based on retrospective collection of data from available records. The data was collected from the blood donor records and registers pertaining to the 10-year period from 2007 to 2016. Samples seroreactive for Hepatitis B and hepatitis $\mathrm{C}$ are recorded and analysed.

\section{RESULTS}

Seroreactivity of Hepatitis B and hepatitis C were recorded and estimated, and their annual and total prevalence and trends studied during the ten-year period. Among the transfusion transmitted infections, Hepatitis B is most prevalent. Total prevalence of Hepatitis B and Hepatitis C is $0.24 \%$ and $0.09 \%$ respectively. Year wise prevalence is variable. $81.4 \%$ of total transfusion transmitted infections are caused by hepatitis B and C.

\section{CONCLUSION}

Viral hepatitis is a common public health problem. The prevalence of hepatitis B and C is high even in healthy young people.

\section{KEY WORDS}

Prevalence, Viral Hepatitis, Hepatitis B, Hepatitis C, Blood Donor Study.

HOW TO CITE THIS ARTICLE: Rajan LL, Suma MS, Harikumar S. Transfusion transmitted hepatitis- a study among blood donors. J. Evolution Med. Dent. Sci. 2018;7(52):5530-5534, DOI: 10.14260/jemds/2018/1224

\section{BACKGROUND}

Viral Hepatitis is the inflammation of liver caused by viruses. There are 5 main hepatitis viruses, referred to as types A, B, $\mathrm{C}, \mathrm{D}$ and $\mathrm{E}$. These 5 types are of greatest concern because of the burden of illness and death they cause and the potential for outbreaks and epidemic spread. In particular, types B and $\mathrm{C}$ lead to chronic disease in hundreds of millions of people and, together, are the most common cause of liver cirrhosis and cancer. Hepatitis B, C and D usually occur as a result of parenteral contact with infected body fluids. ${ }^{1}$

Hepatitis B and hepatitis C are the major causes of acute and chronic liver diseases. The disease attributed to 1.4 million deaths annually. It is estimated that 248 million people are living with chronic HBV infection and 110 million persons are living with HCV-antibody positive, of which 80 million have active viraemic infection.

'Financial or Other Competing Interest': None.

Submission 09-11-2018, Peer Review 06-12-2018,

Acceptance 12-12-2018, Published 24-12-2018.

Corresponding Author:

Dr. Lekshmi Leela Rajan,

Associate Professor (CAP)

Department of Transfusion Medicine and Immunohematology,

Government Medical College, Kollam, Kerala, India.

E-mail:lekshmraj@gmail.com

DOI: $10.14260 /$ jemds $/ 2018 / 1224$
According to WHO Hepatitis B and hepatitis C is 10 times that of global epidemic of HIV infection and chronic hepatitis is a second biggest killer after tuberculosis. ${ }^{1}$

Common modes of transmission for these viruses include receipt of contaminated blood or blood products, invasive medical procedures using contaminated equipment and for hepatitis B transmission from mother to baby at birth, from family member to child, and also by sexual contact.2,3

Hepatitis B and Hepatitis C are transmitted through sharing needles, syringes, or other drug-injection equipment. These viral infections can be acquired by percutaneous exposure. High risk group include sex workers, intravenous drug users, transplant recipients, transfusion dependent patients, those using immunoglobulins, haemodialysis patients and health care workers. $2,3,4,5$

One mode of transmission of viruses is the transfusion of blood products. Blood donors are a group of healthy productive people in the society. Blood samples of donors are tested for Hepatitis B and hepatitis C. Unsafe blood transfusions and the re-use of contaminated injection equipment in medical settings injection drug users are at high risk of getting transfusion transmitted hepatitis. HBV also poses a risk to healthcare workers who sustain accidental needle stick injuries while caring for infected-HBV patients. 2,3,4,5 Safe and effective vaccines are available to prevent HBV. There is no effective vaccine for Hepatitis C. 4,5 
Mandatory testing of these two infections prior to blood and organ transplantation help us to identify the depth of the problem. Blood donors are group of healthy individuals in the community. Blood is collected from donors after a thorough screening procedure including history taking based on donor questionnaire, counselling medical examination. The blood samples are then tested for five infections, Hepatitis B and hepatitis C, HIV, malaria and syphilis. ${ }^{6}$

Every year World Hepatitis Day is observed on 28 July aiming to create awareness among common people about prevention, diagnosis and treatment of viral hepatitis. At the 69th World Health Assembly (Geneva), 194 governments adopted WHO's first Global Health Sector Strategy on Viral Hepatitis (2016-2021) with a goal of eliminating viral hepatitis by $2030 .^{7}$

\section{MATERIALS AND METHODS}

The study was conducted in a tertiary care centre in Kerala which is also a Government Medical College in Kerala. The study is a descriptive study based on retrospective collection of data from available records. The data was collected from the blood donor records and registers pertaining to the 10 year period from 2007 to 2016. All blood units collected in blood banks are tested mandatory for five diseases. Consent for testing was obtained from each donor prior to blood donation. Healthy blood donors were selected by a thorough screening process which included a detailed history taking and physical examination. The donor serum samples were analysed to detect antiHCV antibodies by third generation ELISA test. Seroreactivity to Hepatitis $C$ virus is recorded in the respective screening register. $\mathrm{HBsAg}$ antigen detecting ELISA test is used for Hepatitis B detection. All the samples that were found positive by ELISA on initial testing were repeated in duplicate with the same samples. Samples that were found reactive on repeat testing were considered as positive and included in the study. Any equivocal or indeterminate samples were also discarded considering the safety of blood transfusion but not included in the study. All the donor units collected during the study period in the blood bank as well as outreach camps were included in the study leading to a sample size of 173027 . Descriptive analysis was done on collected data. Estimation of total prevalence during the period was done along with the annual prevalence from the collected data to find out trends. The proportion of positive cases among male and female donors was estimated and Chi square test for proportions was done to find out any significant difference between them.

\section{RESULTS}

Transfusion transmitted hepatitis prevalence study among blood donors is a record based Descriptive study conducted in a blood bank associated with a Tertiary care centre which is also a Government Medical College in Kerala. All blood units collected during the 10-year period are included which is 173027 units collected from January 2007 to December 2016 included. All samples collected were undergone mandatory testing for five diseases. All the samples that were found positive by ELISA on initial testing were repeated in duplicate with the same samples. Samples that were found reactive on repeat testing were considered as positive and included in the study. Any equivocal or indeterminate samples were also discarded considering the safety of blood transfusion but not included in the study.
Blood was collected from donors who visited the blood bank and also from outreach camps conducted in colleges, schools, clubs, mobile blood donation vans and other institutions. Descriptive analysis was done on collected data. Total males donated in this period were 165824 that is $95.84 \%$ males. Total females donated were 7203 . That is 4.16 $\%$ of total donation is females. Females were donated mainly in outreach camps conducted in colleges. $98 \%$ donors were in the age group 18-50 years.

\begin{tabular}{|c|c|c|c|}
\hline Year of Study & Males & Females & Total Donors \\
\hline 2007 & 14181 & 45 & 14226 \\
\hline 2008 & 16643 & 99 & 16742 \\
\hline 2009 & 15489 & 115 & 15604 \\
\hline 2010 & 16541 & 162 & 16703 \\
\hline 2011 & 15776 & 953 & 16729 \\
\hline 2012 & 16595 & 565 & 17160 \\
\hline 2013 & 15342 & 1023 & 16365 \\
\hline 2014 & 16207 & 1656 & 17863 \\
\hline 2015 & 18415 & 1644 & 20059 \\
\hline 2016 & 20635 & 941 & 21576 \\
\hline Total Donors & $\mathbf{1 6 5 8 2 4}$ & $\mathbf{7 2 0 3}$ & $\mathbf{1 7 3 0 2 7}$ \\
\hline \multicolumn{4}{|c|}{ Table 1. Distribution of Donors according to Sex } \\
\hline \multicolumn{4}{|c}{} \\
\hline
\end{tabular}

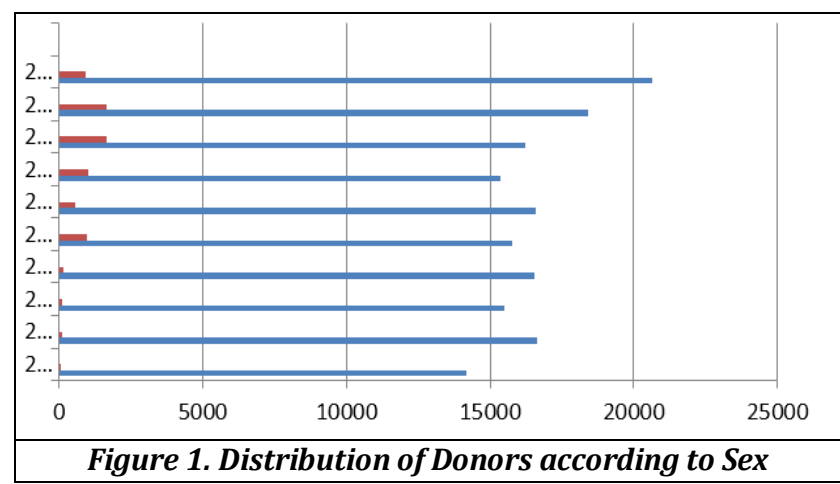

The donor screening process involved a combination of donor education and self-deferral, donor counselling, donor questioning, donor physical examination. Blood samples are collected for serological testing after phlebotomy. All samples were tested mandatory for five Transfusion Transmitted Infections (TTI), namely HIV antibody detection tests, HBsAg antigen detection tests, HCV antibody detection tests, malarial antigen detection tests and Syphilitic antibody detection tests.

\begin{tabular}{|c|c|c|c|c|}
\hline $\begin{array}{c}\text { Year of } \\
\text { Study }\end{array}$ & $\begin{array}{c}\text { HBsAg } \\
\text { Reactivity }\end{array}$ & $\begin{array}{c}\text { Anti HCV } \\
\text { Reactivity }\end{array}$ & $\begin{array}{c}\text { Hepatitis B } \\
\text { and C }\end{array}$ & $\begin{array}{c}\text { Total TTD } \\
\text { Positivity }\end{array}$ \\
\hline 2007 & 61 & 43 & 104 & 133 \\
\hline 2008 & 74 & 22 & 96 & 110 \\
\hline 2009 & 58 & 7 & 65 & 77 \\
\hline 2010 & 55 & 13 & 68 & 79 \\
\hline 2011 & 31 & 6 & 37 & 43 \\
\hline 2012 & 34 & 2 & 36 & 41 \\
\hline 2013 & 26 & 2 & 28 & 32 \\
\hline 2014 & 22 & 27 & 49 & 79 \\
\hline 2015 & 21 & 16 & 37 & 52 \\
\hline 2016 & 37 & 21 & 58 & 64 \\
\hline Total & $\begin{array}{c}419 \\
\text { (59\%) }\end{array}$ & $\begin{array}{c}\text { 159 } \\
\text { (22.4\%) }\end{array}$ & $\begin{array}{c}\text { 578 } \\
\text { (81.4\%) }\end{array}$ & $\mathbf{7 1 0}$ \\
\hline \multicolumn{7}{|c|}{ Table 2. Proportion of Hepatitis B and Hepatitis C } \\
Seroreactivity among all Transfusion Transmitted \\
Infections Reactive Samples \\
\hline \multicolumn{5}{|c|}{} \\
\hline
\end{tabular}


81.4\% of total transfusion transmitted infections are caused by hepatitis B and C. As the majority of donor population are males the seroreactivity also high in males $98.9 \%$. Chi square test done, $\mathrm{p}$ value is 0.00 and hence statistically significant difference in the proportion of hepatitis B positive among males and females. Hepatitis B reactivity comes to $59 \%$ of all other transfusion transmitted infections. Reactivity is high in the first five years than later years.

\section{Proportion of Hepatitis B and Hepatitis C in total Transfusion Transmitted Infections}

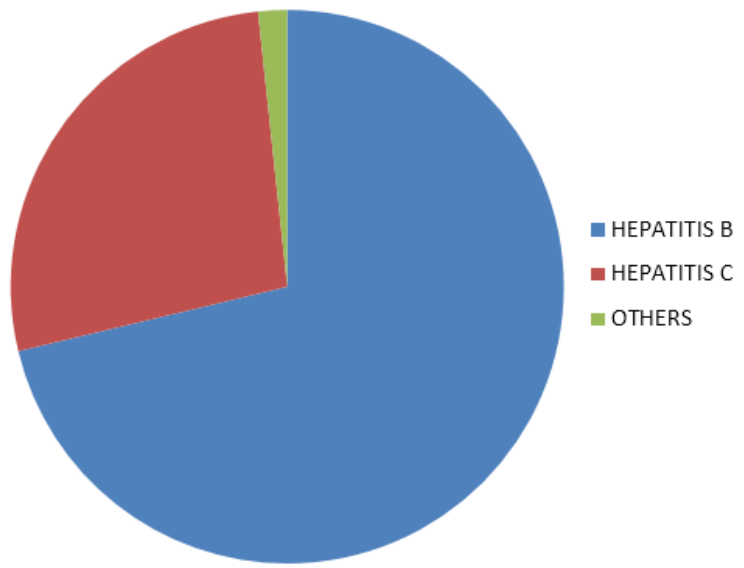

Figure 2. Proportion of Transfusion Transmitted Infections

\begin{tabular}{|c|c|c|c|c|}
\hline $\begin{array}{c}\text { Year of } \\
\text { Study }\end{array}$ & $\begin{array}{c}\text { HBsAg } \\
\text { Reactivity }\end{array}$ & Total & $\begin{array}{c}\text { Prevalence of } \\
\text { Hepatitis B in } \\
\text { Percentage }\end{array}$ & $\begin{array}{c}\text { Prevalence of } \\
\text { Hepatitis B } \\
\text { for every } \\
\mathbf{1 0 0 0 0} \\
\text { Donors }\end{array}$ \\
\hline 2007 & 61 & 14226 & 0.43 & 43 \\
\hline 2008 & 74 & 16742 & 0.44 & 44 \\
\hline 2009 & 58 & 15604 & 0.37 & 37 \\
\hline 2010 & 55 & 16703 & 0.33 & 33 \\
\hline 2011 & 31 & 16729 & 0.19 & 19 \\
\hline 2012 & 34 & 17160 & 0.2 & 20 \\
\hline 2013 & 26 & 16365 & 0.16 & 16 \\
\hline 2014 & 22 & 17863 & 0.12 & 12 \\
\hline 2015 & 21 & 20059 & 0.11 & 11 \\
\hline 2016 & 37 & 21576 & 0.17 & 17 \\
\hline Total & $\mathbf{4 1 9}$ & $\mathbf{1 7 3 0 2 7}$ & $\mathbf{0 . 2 4}$ & $\mathbf{2 4}$ \\
\hline \multicolumn{7}{|c|}{ Table 3. Prevalence of Hepatitis B } \\
\hline
\end{tabular}

\begin{tabular}{|c|c|c|c|c|}
\hline $\begin{array}{c}\text { Year of } \\
\text { Study }\end{array}$ & Anti HCV & $\begin{array}{c}\text { Total } \\
\text { Reactivity }\end{array}$ & $\begin{array}{c}\text { Prevalence } \\
\text { of Hepatitis } \\
\text { C }\end{array}$ & $\begin{array}{c}\text { Prevalence of } \\
\text { Hepatitis C } \\
\text { for every 10000 } \\
\text { Donors }\end{array}$ \\
\hline 2007 & 43 & 14226 & 0.30 & 30 \\
\hline 2008 & 22 & 16742 & 0.13 & 13 \\
\hline 2009 & 7 & 15604 & 0.04 & 4 \\
\hline 2010 & 13 & 16703 & 0.08 & 8 \\
\hline 2011 & 6 & 16729 & 0.04 & 4 \\
\hline 2012 & 2 & 17160 & 0.01 & 1 \\
\hline 2013 & 2 & 16365 & 0.01 & 1 \\
\hline 2014 & 27 & 17863 & 0.15 & 15 \\
\hline 2015 & 16 & 20059 & 0.08 & 8 \\
\hline 2016 & 21 & 21576 & 0.10 & 10 \\
\hline Total & $\mathbf{1 5 9}$ & $\mathbf{1 7 3 0 2 7}$ & $\mathbf{0 . 0 9}$ & $\mathbf{9}$ \\
\hline & \multicolumn{7}{|c|}{ Table 4. Prevalence of Hepatitis C } \\
\hline
\end{tabular}

$98.7 \%$ of the Hepatitis C infection occurred in males. Chisquare test done.

$\mathrm{P}$ value is 0.07 . The difference in the proportion of having hepatitis C among males and females is not statistically significant.

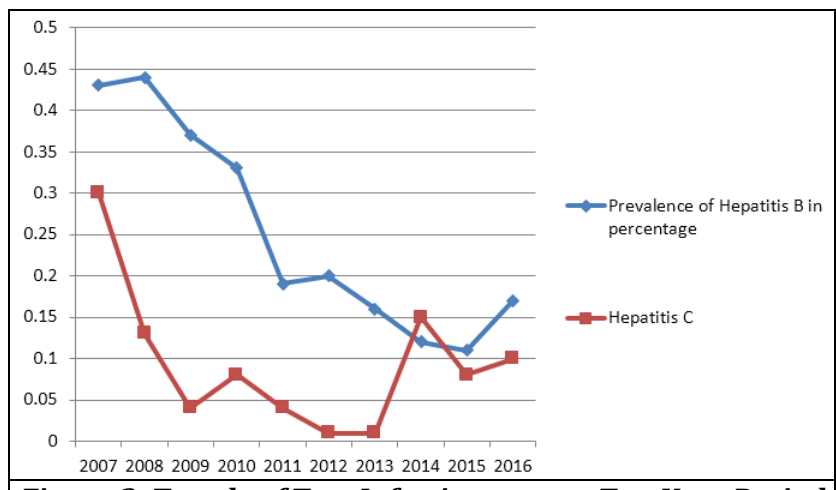

Figure 3. Trends of Two Infections over a Ten-Year Period

\section{DISCUSSION}

Hepatitis B is a major threat to global public health. As per WHO updates some 257 million people worldwide are chronically infected with HBV. Chronically infected with hepatitis B is defined as hepatitis B surface antigen positive for at least 6 months. HBV can cause chronic infection and puts people at high risk of death from cirrhosis and liver cancer. The disease causes around $40 \%$ of all primary liver cancers - the second most deadly cancer, causing more than 887000 deaths each year. Transfusion of blood and blood products are increasing nowadays leading to the possibility of spreading transfusion transmitted hepatitis. Modern transfusion therapy guidelines advocate component therapy. Thus, infectious agents in one person may spread to multiple recipients. The problem of window period varies from few days to months. Hepatitis B prevalence is highest in the WHO Western Pacific Region and the WHO African Region, where $6.2 \%$ and $6.1 \%$ respectively of the adult population is infected. In the WHO Eastern Mediterranean Region, the WHO South-East Asia Region and the WHO European Region, an estimated $3.3 \%, 2.0 \%$ and $1.6 \% \%$ of the general population is infected, respectively. $0.7 \%$ of the population of the WHO Region of the Americas is infected. ${ }^{1-5}$

In the Middle East and the Indian subcontinent, an estimated $2-5 \%$ of the general population is chronically infected. ${ }^{8}$

Based on the prevalence of Hepatitis B surface Antigen the different areas of world are classified as high $(\geq 8 \%)$, intermediate $(2-7 \%)$ or low $(<2 \%)$. India comes in intermediate but India with one-fifth population burden accounts for a large proportion of worldwide HBV burden. India harbours $10-15 \%$ of the entire pool of HBV carriers of the world. It has been estimated that India has around 40 million HBV carriers. Prevalence of Hepatitis B among general population ranges from $0.1 \%$ to $11.7 \%$, between $2 \%$ and $8 \%$ in most of the studies. Due to thorough donor screening process HBsAg prevalence in blood bank data was much lower vary from $0.2-4 \%$ in most of the studies. However, prevalence of Hepatitis B study is important to tackle the spread of the disease. ${ }^{9}$

Globally Hepatitis C virus is estimated to infect 170 million people, that is $3 \%$ of world population. Hepatitis $\mathrm{C}$ virus create a huge burden of disease in the form of chronic 
progressive liver diseases. Hepatitis $\mathrm{C}$ has become one of the major causes of liver cancer and one of the most common indication for liver transplantation. In 2015, an estimated 71 million people were living with chronic HCV infection according to WHO and only 20 percent of those infected with HCV had been tested to know the status.

According to WHO, the most affected regions are WHO Eastern Mediterranean and European Regions, with the prevalence of $2.3 \%$ and $1.5 \%$ respectively. Prevalence of HCV infection in other WHO regions varies from $0.5 \%$ to $1.0 \%$. Depending on the country, Hepatitis $\mathrm{C}$ virus infection can be concentrated in certain populations (For example, among people who inject drugs) and/or in general populations. ${ }^{1-5}$

Most of the prevalence studies of hepatitis comes from blood bank donor screening data. Most of the studies are retrospective analysing the records.

As in our studies almost all studies showed males as predominant donors. In 2007 and 2008 there were only few female donors those who donated in blood banks. In 2009 onwards, more and more outreach camps were conducted and promoted female donation. Outreach camps in Women's colleges encouraged female donors. A study from rural Vietnam showed a high prevalence of HBV, $11.4 \% \%^{10}$

In different parts of India various studies were published. In Western India, one study from Ahmadabad HBV and HCV were $0.887 \%$ and $0.101 \%$ respectively. ${ }^{11}$

In a 10-year study conducted among blood donors in North India Makroo et al found 1.18\% HBV seroprevalence and $0.39 \%$ donors reactive to HCV antibody detection tests. A slight increase in the prevalence of HCV was noted by Makroo etal in a later study. ${ }^{12,13}$ In a study from Andhra Pradesh, the seroreactivity of HBV and HCV were $1.41 \%$ and $0.84 \%$ respectively. ${ }^{14}$ In a study from Punjab, seroreactivity of HBV and HCV were $0.75 \%$ and $1.79 \%$ respectively. 15

In Madhya Pradesh a study among blood donors showed reactivity of $\mathrm{HBV}$ and $\mathrm{HCV}$ were $1.18 \%$ and $0.33 \%$ respectively. ${ }^{16}$

Various studies among blood donors from different parts of Kerala were published. A study from Trivandrum, Kerala during 1994-1999, showed a prevalence rate of HBV as $1.26 \%$ and HCV seroreactivity, $1.44 \% .17$ another study from Central Kerala showed a prevalence rate of HBV as $0.2 \%$ and HCV $0.9 \% .18$ in the present study the prevalence of hepatitis B is $0.24 \%$.which is similar to other blood donor studies.

Present study showed a Anti HCV prevalence rate of 0.09 $\%$ which is also identical from other studies from Kerala. A five-year prevalence study from the same author found a prevalence of Hepatitis C as $0.072 \% .^{19}$

The trends of two infections in a ten-year period is studied. Both infections showing a declining trend. This corresponds with the implementation of voluntary blood donation and more outreach camps conducted in colleges and other institutions. There is a declining trend in all TTI from 2009 onwards due to strict voluntary blood donation.

Transfusion transmitted infections (TTI) continue to be a threat to safe transfusion practices. The various markers of infection appear at different times after infection. Each TTI has window period, ranging from a few days to months, depending on the infectious agent, the screening marker used, and the screening technology employed. Hepatitis B and hepatitis $\mathrm{C}$ are more in transfusion dependent patients, studies on haemodialysis patients are all pointing towards it. 20

The occurrence of hepatitis B positivity among family members of HBsAg-positive patients was $14.53 \%$ in one study. This prevalence was twenty-eight times more than the community prevalence of HBV infection in population, which was earlier found to be $0.52 \%$ by the same group. ${ }^{21}$

In a community-based study done in Kollam, Kerala which searched for the risk factors of hepatitis B found that there is a strong association with laboratory testing and transmission of hepatitis B. Most of the positive patients visited local laboratories within a 6 months period. ${ }^{22}$

Hepatitis B virus (HBV) takes a huge human and economic toll. Despite this, research into HBV is drastically underfunded, to the point that it was recently compared to a neglected tropical disease. Hepatitis B is an important occupational hazard for health workers. Hepatitis B can be prevented by currently available safe and effective vaccine.

\section{CONCLUSION}

Viral hepatitis has become a public health challenge. It is a major global health problem. Transfusion transmitted hepatitis continuing to be a problem in safe transfusion practices. Community awareness is very important in preventing the spread of the disease. Awareness right from the donor selection is very important. Newer diagnostic techniques like NAT may be employed to make products safer. Widespread screening and large-scale population studies are required for determination of the actual prevalence.

\section{REFERENCES}

[1] https://www.afro.who.int/health-topics/hepatitis Accessed on 10-09-2018.

[2] WHO factsheet on Hepatitis B. Accessed on 10-092018. http://www.who.int/en/news-room/factsheets/detail/hepatitis-b

[3] CDC Hepatitis B. Accessed on 10-09-2018. https://www.cdc.gov/hepatitis/hbv/index.htm

[4] WHO factsheet hepatitis. Accessed on 10-09-2018. http://www.who.int/en/news-room/factsheets/detail/hepatitis-c

[5] CDC Hepatitis C. Accessed on 10-09-2018. https://www.cdc.gov/hepatitis/hcv/index.htm

[6] http://www.who.int/bloodsafety/publications/bts_gu ideline_donor_suitability/en/ Accessed on 10-092018.

[7] Press Information Bureau, Government of India, Ministry of Health and Family Welfare, 28-July-2018.

[8] http://origin.who.int/mediacentre/news/releases/20 17/global-hepatitis-report/en/ Accessed on 10-092018.

[9] Puri P. Tackling the Hepatitis B disease burden in India. J Clin Exp Hepatol 2014;4(4):312-9.

[10] Viet L, Lan NT, Ty PX, et al. Prevalence of Hepatitis B and Hepatitis $\mathrm{C}$ virus infections in potential blood donors in rural Vietnam. Indian J Med Res 2012;136(1):74-81.

[11] Shah N, Shah JM, Jhaveri P, et al. Seroprevalence of HBV, HCV, HIV and syphilis among blood donors at a 
tertiary care teaching hospital in Western India. Gujarat Medical Journal 2013;68(2):35-9.

[12] Makroo RN, Walia RS, Chowdhry $M$, et al. Seroprevalence of anti-HCV antibodies among blood donors of North India. Indian J Med Res 2013;138(1):125-8.

[13] Makroo RN, Hedge V, Chowdhry $M$, et al. Seroprevalence of infectious markers and their trends in blood donors in a hospital based blood bank in North India. Ind J Med Res 2015;142(3):317-22.

[14] Bhawani Y, Rao PR, Sudhakar V. Seroprevalence of transfusion transmissible infections among blood donors in a tertiary care hospital in Andhra Pradesh. Biology and Medicine 2010;2(4):45-8.

[15] Kaur H, Mannan R, Manjari DM. Seroprevalence of the blood borne infection in blood donors: our 11 year (2001 -2011) experience in a tertiary care teaching hospital at Amritsar (Punjab). International Journal of Advanced Research 2014;2(6):967-71.

[16] Singh SK. Transfusion transmitted infection among the blood donors in Central India: a tertiary care hospital based study. Paripex Indian Journal of Research 2015;4(4).

[17] Mathai J, Sulochana PV, Satyabhama S, et al. Profile of transfusion transmissible infections and associated risk factors among blood donors of Kerala. Indian Journal of Pathol Microbiol 2002;45(3):319-22.
[18] Shailaja TS, Mohankumar A, Sankari D, et al. Seroprevalence of Hepatitis B and Hepatitis C viral infections in Central Kerala. Indian Journal of Applied Research 2016;6(5):39-41.

[19] Rajan LL, Suma MS, Kala VL, et al. Seroprevalence of hepatitis $\mathrm{C}$ virus among blood donors in a tertiary care centre in Kerala. J Evolution Med Dent Sci 2017;6(50):3852-6.

[20] Malhotra R, Soin D, Grover P, et al. Hepatitis B virus and hepatitis $\mathrm{C}$ virus co-infection in hemodialysis patients: a retrospective study from a tertiary care hospital of North India. J Nat Sci Biol Med 2016;7(1):72-4.

[21] Kavitha R, Ramachandran TM, Varghese T. Intrafamilial occurrence of Hepatitis B virus (HBV) infection and the profile of liver disease in close relatives of patients with HBV infection. Journal of Clinical and Experimental Hepatology 2011;1(Suppl 1):6.

[22] Rakesh PS, Usha S, Renjini BA, et al. Risk factors of hepatitis B infection: a community based case control study from Southern India. Indian Journal of Basic and Applied Medical Research 2013;3(1):172-80. 